\title{
Cervical cancer: what's new?
}

\author{
José Carlos Sadalla ${ }^{1 *}$, Jurandyr Moreira de Andrade ${ }^{2}$, Maria luiza Nogueira Dias Genta ${ }^{3}$, Edmund Chada Baracat ${ }^{4}$ \\ ${ }^{1}$ PhD Assistant Professor, Mastology Sector, Division of Gynecology, Department of Obstetrics and Gynecology and the Institute of Cancer of the State of São Paulo, Hospital das Clínicas, Faculdade de Medicina, \\ Universidade de São Paulo (FMUSP), São Paulo, SP, Brazil \\ ${ }^{2}$ Full Professor at the Department of Gynecology and Obstetrics, Faculdade de Medicina de Ribeirão Preto, Universidade de São Paulo, Ribeirão Preto, SP, Brazi \\ ${ }^{3}$ Assistant Professor, Mastology Sector, Division of Gynecology, Department of Obstetrics and Gynecology and the Institute of Cancer of the State of São Paulo, Hospital das Clínicas, FMUSP, São Paulo, SP, Brazil \\ ${ }^{4}$ Full Professor, Division of Gynecology, Department of Obstetrics and Gynecology, FMUSP, São Paulo, SP, Brazil
}

\begin{abstract}
SUMMARY
Study conducted at the Mastology Sector, Division of Gynecology, Department of Obstetrics and Gynecology, and the Institute of Cancer of the State of São Paulo, Hospital das Clínicas, Faculdade de Medicina, Universidade de São Paulo (FMUSP), São Paulo, SP, and the Sector of Mastology and Gynecologic Oncology at Faculdade de Medicina de Ribeirão Preto (HCRP), Ribeirão Preto, SP, Brazil

Article received: $10 / 20 / 2015$ Accepted for publication: 10/23/2015

*Correspondence:
\end{abstract} Address: Av. Ibirapuera, 2907, cj. 720 Indianópolis Postal code: 04029-200 São Paulo, SP - Brazil jcsadalla@gmail.com

http://dx.doi.org/10.1590/1806-9282.61.06.536

Financial support: none

\section{INTRODUCTION}

Cervical cancer is the most frequent pelvic cancer among women in Brazil. In the gynecological sphere, it is the second most frequent, immediately after breast cancer. It is the fourth leading cause of cancer death in the country, with estimated 15,590 new cases (2014) and 5,430 deaths (2013). ${ }^{1}$

Treatment of cervical cancer is planned depending on the clinical stage of the disease, ranging from surgery alone to a combination of radiation, chemotherapy and surgery in special situations. However, the side effects and morbidity caused by these therapies often deeply affect the quality of life of patients. Another important point is that the staging of cervical cancer is done clinically, including the results of imaging tests, and the initial classification should not be changed depending on surgical findings. The most recent classification of cervical cancer stages by the International Federation of Gynecology and Obstetrics (Figo) is shown in Table 1.

In order to provide important information to better assist the patients, reducing the morbidity and optimizing the treatment of this malignancy, this article will ad- dress recent advances of knowledge on cervical cancer. The topics selected include the role of surgery in different stages, fertility preservation, the role of the sentinel lymph node technique, indications and techniques for radiotherapy and chemotherapy, and also some special situations.

\section{THE ROLE OF SURGERY IN THE INITIAL STAGES}

Surgery as treatment alone is employed for the initial stages (carcinoma in situ, micro-invasive, and invasive stage IB1), but depending on the diameter of the lesion, some centers treat IIA1 cancers surgically. However, this approach is not recommended as initial therapy of IB2 tumors (limited to the cervix and having a diameter above $4 \mathrm{~cm}$ ). ${ }^{2-5}$ For lesions in stage 0 (in situ carcinoma), conization with free margins is sufficient. ${ }^{2-5}$

In stage IA1 (micro-invasion less than $3 \mathrm{~mm}$ ), the choice will depend on the patient's desire to preserve fertility, and whether there is lymphovascular invasion. After conization, if the cone margins are free and there is no lymphovascular invasion, clinical monitoring alone is recommended. It is recommended to avoid fragmenta- 
TABLE 1 Staging of cervical cancer (Figo 2009*).

\begin{tabular}{|c|c|}
\hline Stage & Description \\
\hline 0 & In situ carcinoma \\
\hline I & Carcinoma strictly confined to the cervix (extension to the uterine corpus should be disregarded) \\
\hline IA & $\begin{array}{l}\text { Invasive cancer identified only microscopically. Invasion is limited to measured stromal invasion with a maximum depth of } \\
5 \mathrm{~mm} \text { and no wider than } 7 \mathrm{~mm}\end{array}$ \\
\hline IA1 & Measured invasion of stroma $\leq 3 \mathrm{~mm}$ in depth and $\leq 7 \mathrm{~mm}$ width \\
\hline IA2 & Measured invasion of stroma $>3 \mathrm{~mm}$ and $\leq 5 \mathrm{~mm}$ in depth and $\leq 7 \mathrm{~mm}$ width \\
\hline IB & Clinical lesions confined to the cervix, or preclinical lesions greater than stage IA \\
\hline IB1 & Tumor $\leq 4 \mathrm{~cm}$ \\
\hline IB2 & Tumor $>4 \mathrm{~cm}$ \\
\hline IIA & Involvement of up to the upper $2 / 3$ of the vagina \\
\hline IIA1 & Tumor $\leq 4 \mathrm{~cm}$ \\
\hline IIA2 & Tumor $>4 \mathrm{~cm}$ \\
\hline IIB & Parametrial tumor involvement \\
\hline III & $\begin{array}{l}\text { The carcinoma has extended onto the pelvic sidewall and involves the lower third of the vagina and/or hydronephrosis and/ } \\
\text { or non-functioning kidney }\end{array}$ \\
\hline IIIA & Involvement of the lower vagina but no extension onto pelvic sidewall \\
\hline IIIB & Extension onto the pelvic sidewall, or hydronephrosis/non-functioning kidney \\
\hline IV & $\begin{array}{l}\text { The carcinoma has extended beyond the true pelvis or has clinically involved the mucosa of the bladder and/or rectum (prov- } \\
\text { en by biopsy). Note: bullous edema is not considered stage IV. }\end{array}$ \\
\hline IVA & Spread to bladder and/or rectum \\
\hline IVB & Spread to distant organs \\
\hline
\end{tabular}

tion of the specimen and thermal artifacts, which may hinder the histological analysis, and, therefore, in such cases scalpel conization is preferred. If there is no interest in preserving fertility, the recommendation is that the surgery should include plain hysterectomy. Bilateral salpingectomy associated with hysterectomy to prevent ovarian carcinoma is also recommended. However, if there is lymphovascular invasion (very rare situation for this depth of invasion), radical hysterectomy (Class B according to Morrow and Querleau ${ }^{6}$ with resection of the parametrium at the level of ureter) and pelvic lymphadenectomy, or sentinel lymph node technique can be indicated. If the patient wants to preserve fertility, radical trachelectomy can be offered.

As for IA2 and IB1 stages, for patients who do not want to preserve fertility, the best alternative ${ }^{7}$ is radical hysterectomy class C, by Morrow and Querleau, with resection of parametrium at the level of internal iliac artery, which corresponds to the classical Werteim-Meigs operation, or type III-V Piver-Rutledge, in addition to pelvic lymphadenectomy. For these stages (IA2 and IB1), the sentinel lymph node technique can be proposed to prevent radical lymphadenectomy and risks of associated morbidities (evidence and recommendation 2B for sen- tinel lymph node). In these stages, if the patient has a clinical contraindication or if she does not accept the surgery, the choice becomes exclusive radiotherapy, using teletherapy supplemented by brachytherapy. Radical surgical procedures can be performed by laparotomy or laparoscopy, including robotic surgery. ${ }^{8}$

Surgery as initial treatment is not indicated for IB2, IIA1 and IIA2 cancers. The probability of positive margins or other indications for radiotherapy or chemotherapy in these stages is very high, around $80 \%$. We know that the addition of adjuvant therapies to surgery (chemoradiation) increases morbidity, worsening the quality of life of the patient. ${ }^{9-11}$

An important component of the treatment of cervical carcinoma in the early stages is adding radiation therapy in situations at high risk for local or systemic recurrence. Poor prognostic indicators are obtained from surgical specimens and include the following: positive pelvic lymph nodes, parametrial involvement or positive surgical margin. More recently, another category of prognostic indicators was added to clinical practice and applies to patients without any of the cited criteria. These, considered as minor criteria, are: diameter of the primary tumor associated with lymphovascular invasion, or 
deep invasion of the cervical stroma. ${ }^{12}$ The presence of any of the major criteria, or a combination of the Sedlis criteria, is an indication for adjuvant pelvic radiotherapy, plus teletherapy associated with brachytherapy in cases of worse prognosis. The addition of chemotherapy concurrent with radiation therapy (cisplatin in weekly doses) for cases with higher risk of recurrence, especially for patients with more than one positive lymph node, showed benefits in terms of overall survival and recurrence-free interval. ${ }^{13}$

\section{Treatment of Locally adVANCED CERVICAL TUMORS}

Tumors at stage IB2, IIA 2, III and IV are included in this category. For all these situations, the recommended treatment since 1999 based on several multicenter randomized trials is the combination of chemotherapy and radiation. The regimen considered standard is IV administration of cisplatin weekly $\left(40 \mathrm{mg} / \mathrm{m}^{2}\right)$ associated with radiotherapy (5 sessions per week for six weeks). ${ }^{14}$ For best results, the treatment as outlined above should last between 50 and 55 days. This approach, compared with radiotherapy alone, led to an overall survival benefit of $8 \%, 9 \%$ for local relapsefree interval, and $7 \%$ in recurrence-free interval. However, there is increased toxicity and even logistical problems that prevent treatment as required in most of these cases. Adjuvant hysterectomy is a procedure still under debate. The guidelines mention the procedure for situations where the radiation cannot be completed (degree of recommendation 3) ${ }^{13}$ However, response to radiotherapy is worse for adenocarcinomas, ${ }^{9,15,16}$ and a Brazilian study showed high rates of residual tumor in the surgical specimens of patients who underwent surgery 3-4 weeks after completion of treatment with radiotherapy and chemotherapy. ${ }^{16}$ When surgery is indicated, salpingo-oophorectomy should be indicated along with hysterectomy $y^{9,15,16}$ considering ovarian failure caused by radiotherapy.

The limited results of chemoradiation for locally advanced tumors, especially related to small impact on reducing recurrences at a distance, led to the search for new strategies and the application of additional cycles of chemotherapy after completion of the initial treatment. ${ }^{17}$ The most studied drugs are cisplatin, combined or not with gemcitabine, ${ }^{18-22}$ and paclitaxel combined with carboplatin. Despite promising results, with improved survival and disease-free interval, there is substantial increase in toxicity with additional cycles of chemotherapy. Currently, two international phase 3 studies are in progress. The drugs studied are carboplatin and paclitaxel in four cycles after chemoradiotherapy (ANZGOG 0902/ GOG
0274/NCT01414608 and Radiation Therapy Oncology Group [RTOG] 0724/NCT00980954). ${ }^{22}$ Another alternative for the treatment of locally advanced lesions is neoadjuvant chemotherapy followed by surgery in cases with good response. Although not recommended as a standard therapy, this approach is employed in about $25 \%$ of patients with locally advanced tumors. Although not indicated in the guidelines as an alternative ${ }^{23}$ non-randomized studies and meta-analyze ${ }^{24}$ show that this treatment gives better results than radiotherapy alone. ${ }^{25}$ The metaanalyzes show a reduction of up to $35 \%$ in the risk of death, and gain of $15 \%$ in survival after 5 years, compared to the use of radiotherapy alone..$^{14,17}$ It is also observed reversal of intermediate and high risk indicators, such as parametrial invasion, depth of cervical invasion and tumor diameter. ${ }^{23}$ The only randomized study comparing this treatment alternative with chemo-sensitization is in patient follow-up phase (EORTC55994/NCT00039338) and its results will be presented in 2018 .

\section{FERTILITY PRESERVATION}

To preserve fertility, conservative surgery (with preservation of uterine body) and ovarian transposition are discussed.

In patients without children and with initial tumors of the cervix, radical trachelectomy is an alternative employed for some time. This surgery involves removing the cervix, along with parametria, proximal third of the vagina and pelvic lymph nodes. The abdominal approach allows better dissection of the parametria but the vaginal route can be used by trained teams. For lymphadenectomy, laparoscopy is the preferred option. Trachelectomy is considered a safe procedure if the following selection criteria are used: usual histology (squamous cell carcinoma or adenocarcinoma, but not neuroendocrine tumors), tumor size less than $2 \mathrm{~cm}$ (confirmed on physical examination and MRI of the pelvis), no disease beyond the cervix (confirmed by CT, MRI or PET-CT), tumor-free pelvic lymph nodes, and surgical specimen with free margins. ${ }^{26-28}$ However, we know that the removal of parametria and proximal third of the vagina affects the future obstetric condition of the patient, with higher frequency of miscarriages and premature births. Thus, in view of the low probability of parametrial involvement in patients with stage IA2 and IB1 (tumor measuring up to $2 \mathrm{~cm}$ ), conization to obtain clear margins associated with pelvic lymphadenectomy has been studied without parametrectomy and colpectomy in these situations. ${ }^{3,4}$ Another approach to IB1 tumors is the use of neoadjuvant chemotherapy prior to trachelectomy. ${ }^{29}$ 
For patients with cancer at more advanced stages or for those not eligible for conservative treatment, one option is ovarian transposition, with the purpose of maintaining hormonal function and ovarian reserve. Surgery consists of releasing the tube and ovary from the pelvic infundibulum, attaching them above the edge of the pelvis, which is the cranial limit for pelvic radiotherapy fields. It is suggested placing clips on the new topography of the annexes, in order to identify these structures later on imaging studies. Keep in mind the risk of ovarian metastasis from cervical carcinoma, which is $0.6 \%$ for squamous cell carcinomas and $6 \%$ for adenocarcinomas, requiring careful evaluation during surgery and removal of suspicious attachments. The success rate is quite variable, and often there is anticipation of menopause in cases treated with transposition. ${ }^{30}$

Some of this variation is due to concurrent or adjuvant chemotherapy, which implies a high chance of ovarian failure induced by the chemo in patients older than 35 years. ${ }^{31-33}$ Other approaches to preserve fertility include advanced procedures such as ovulation induction and oocyte retrieval, in vitro fertilization and embryo freezing, and preservation of ovarian tissue for reimplantation.

\section{Sentinel Lymph NOde ROLE IN the tReAtMent OF CERVICAL CANCER}

The rationale for the use of sentinel lymph node (SLN) technique, such as in the case of breast carcinomas, is that this is the first lymph node that receives drainage from the tumor. Thus, if it is disease-free, the other nodes will also be. And the patient is spared complete lymph node dissection, associated with high morbidity. The main study on the use of this technique to treat cervical carcinomas is the SENTICOL trial, which showed high sensitivity for detection of sentinel lymph node (92\%), high negative predictive value (98.2\%), and no false-negative cases when there was bilateral identification of sentinel lymph nodes. ${ }^{34}$ Other studies have shown similar results. ${ }^{35-37}$

However, the following criteria must be met: the technique is indicated for tumors in stages IA2, IB1 and IIA1 (tumor up to $4 \mathrm{~cm}$ ), except for cases in which there is reduced sensibility using the method, such as in tumors sized more than $2 \mathrm{~cm}$; absence of lymph node involvement (on imaging and intraoperative); bilateral identification of the sentinel lymph node (at least one node in each hemi-pelvis). The accuracy of the method is improved by lymph nodal "ultra-staging" (serial sections of the sentinel lymph node). ${ }^{36,37}$ Nevertheless, it cannot be performed during surgery, and, if the nodes are positive, a second operation is needed. The SENTICOL II trial is cur- rently in progress with removal of the sentinel lymph node alone, without lymphadenectomy, in cases of negative SLN. It will, therefore, be possible to verify whether this procedure can be regarded as the gold standard.

\section{AdVANCES IN RADIOTHERAPy fOR CERVICAL CANCER}

With regard to radiotherapy, the novelty is the planning of external radiation therapy (teletherapy) and brachytherapy guided by magnetic resonance imaging (MRI). For study of the cervix and pelvis, as a whole, MRI showed image resolution better than computed tomography (CT), with better definition of anatomical planes. Thus, a better definition of the fields would be possible, minimizing side effects and improving tolerability to treatment with lower toxicity in bone marrow, bladder and rectum. The existing studies that adopt historical controls for comparison show improved local control and survival, especially in the treatment of advanced tumors (stage IIIB). ${ }^{38-}$

${ }^{42}$ But there are no prospective studies confirming these results. Moreover, the application of these radiotherapy techniques almost quadruples the time spent with each patient, making it difficult to use in most public services, where there are patients awaiting radiotherapy for a considerable time.

\section{AdVANCES IN SYSTEMIC TREATMENT OF RECURRENT CERVICAL CANCER}

With respect to chemotherapy, we now present some advances in the treatment of patients with metastatic disease and the role of antiangiogenic and immunogenic therapies. For the treatment of recurrent cervical cancer, various approaches can be employed depending on the previous treatment, and where the recurrence was detected. Thus, radiation may be an option if it has not been used before, and surgeries such as rescue hysterectomy may be the choice in cases previously treated with radio and chemotherapy. Another alternative rarely used is anterior, posterior or total pelvic exenteration. Most cases, however, have been treated with chemotherapy. Several prospective studies have shown that the schemes based on the use of cisplatin ${ }^{43}$ have no significant impact on survival. The use of carboplatin leads to reduction of toxicity but has no better results in terms of survival.

A substantial gain in survival was observed in a prospective phase 3 study (GOG 240). In this study, patients received one of two chemotherapy regimens, with or without bevacizumab as angiogenesis inhibitor (total of 4 arms). The drug is a monoclonal antibody directed to vascular endothelial growth factor (VEGF). In the popula- 
tion included in the study, $75 \%$ had received prior treatment with cisplatin for recurrent disease. The use of bevacizumab led to improved overall response, progression-free time and survival. ${ }^{4-46}$

There was benefit for patients with recurrent disease in previously irradiated areas. Adverse effects included neutropenia, hypertension (grade 3), gastrointestinal fistula, and thromboembolism. However, the use of targeted therapy allowed an improvement in overall survival compared to chemotherapy alone. Other agents with anti angiogenic activity that proved useful in the treatment of other malignancies are being investigated for cervical cancer, such as sunitinib, pazopanib, lapatinib and cediranib. ${ }^{44}$

The goal of immune therapy in cervical cancer is to modify the patient's immune response leading to the elimination of cancer cells. One approach explores the relationship of this malignancy with the human papilloma virus (HPV). An Indian study of a vaccine with HPV-induced E7 protein, together with attenuated bacterium (Listeria monocytogenes) as a vector, in over 100 women with refractory or recurrent cervical cancer ${ }^{47}$ showed promising results. After six months, $63 \%$ of patients were alive and 12 patients had partial or complete response. ${ }^{47} \mathrm{An}$ other approach is the induction of regulatory cytotoxic $\mathrm{T}$ lymphocyte-associated molecule 4 (CTLA-4), which is important for activation of cellular immune response. Monoclonal antibody ipilimumab blocks CTLA-4 and promotes antitumor immunity, generating effective immune response against the tumor. This drug is in a phase 1 study (GOG 9929/NCT01711515). ${ }^{20}$ Last, another possibility being studied for cervical cancer is that of the inhibitory receptor 1 of cell death (PD-1). When attached to its ligand PD-L1, which is found on tumor cells and leads to blockage of effective antitumor immune response, antibodies to both proteins may restore effective immune response. $^{20}$

\section{Special situations}

In this topic, we will discuss the treatment of patients with involvement of para-aortic lymph nodes, the role of para-aortic lymphadenectomy, and surgical indication in local recurrences (pelvic).

The two most important prognostic factors in cervical cancer, in addition to staging, are tumor size and lymph node involvement. Among the patients with locally advanced tumors (IIB or higher), 15-30\% have para-aortic lymph node involvement. Imaging studies CT, MRI or positron emission computed tomography (PET-CT) have high rates of false negatives. ${ }^{48-50}$ PET-CT has better accuracy, but fails in about $10-20 \%$ of cases (false negatives in para-aortic region). The objective of investigating lymph nodes in this region would be to select cases for treatment with para-aortic field. However, studies in which routine para-aortic lymphadenectomy was performed in locally advanced tumors showed worse prognosis of patients, even with more aggressive adjuvant treatment, such as extending the radiotherapy field to the para-aortic region. Benefit with increased survival to justify a para-aortic lymphadenectomy was observed in patients with negative PET-CT results, and with microscopic disease found only in pathological examination of the para-aortic lymph nodes. ${ }^{51-53}$ Apparently, patients with the disease in paraaortic lymph nodes represent a group in which even radiotherapy applied directly to these lymph nodes associated with chemotherapy, or chemotherapy alone, is not able to improve prognosis.

Pelvic recurrence is a failure event that compromises the survival and quality of life of patients. In such cases, surgical treatment of choice is pelvic exenteration, a procedure that is re-assessed whenever progress is achieved in the areas of surgery, supportive therapy and imaging evaluation. This surgery may be divided into anterior, posterior or total. Anterior exenteration comprises the removal of the recurrent tumor in addition to the bladder compartment. Posterior exenteration refers to the removal of the rectum in addition to the tumor. Last, total exenteration includes the removal of both the bladder and rectum. Another more recent classification divides surgery into categories (supralevator, infralevator, and infralevator with vulvectomy) that are chosen based on the extent of the recurring disease. ${ }^{54,55}$ Due to high rates of complications and mortality associated with this surgery, it should be reserved for much selected cases. It is especially suitable for pelvic recurrence after chemoradiation and when the surgeon anticipates the possibility of obtaining surgical margin, a prerequisite for cure.

Selection criteria include centered relapse with negative lymph nodes and no visceral metastases. ${ }^{54,55}$ As preoperative assessment, all the candidates for pelvic exenteration should undergo PET-CT to rule out distant disease. PET-CT is the imaging study with greater accuracy to detect cervical cancer recurrences. ${ }^{56-58}$ As the occurrence of positive lymph nodes is one of the most frequent reasons to quit exenteration during surgery, prior assessment of pelvic and para-aortic lymph nodes by laparoscopy may be an alternative.

Successful exenteration depends on the following preoperative prognostic factors: tumor size, time from initial treatment to recurrence (disease-free survival) and tumor histology. Tumor size greater than $5 \mathrm{~cm}$, recur- 
rence after less than two years of initial treatment, and histological type of squamous cell carcinoma (SCC) are associated with poor prognosis. ${ }^{54,55}$ Regarding postoperative prognostic factors, worst outcome is found in the presence of positive meso-rectal lymph nodes, positive lymphovascular invasion, and margins compromised by tumor, with survival after two years around $10 \% .54,55$

\section{Resumo}

Câncer de colo do útero: o que há de novo?

O câncer de colo uterino é o câncer ginecológico mais frequente em nosso meio. Entre as mulheres, é o segundo mais frequente, atrás apenas do câncer de mama. É a quarta causa de morte por câncer no Brasil, com estimativa de 15.590 casos novos (2014) e com 5.430 mortes (2013). No intuito de atualizar informações para a melhora do prognóstico, redução da morbidade e otimização do tratamento dessa neoplasia, serão abordados neste artigo os avanços nos conhecimentos sobre o câncer cervical. Entre os temas apresentados, estão o papel da cirurgia nos diferentes estádios, o tratamento dos carcinomas localmente avançados, a preservação da fertilidade, o papel da técnica do linfonodo sentinela, indicações e técnicas da radio e quimioterapia, além de situações especiais.

Palavras-chave: câncer, colo do útero, exenteração pélvica, preservação da fertilidade, biópsia de linfonodo sentinela, braquiterapia, quimioterapia.

\section{References}

1. INCA - Instituto Nacional de Câncer José Alencar Gomes da Silva. http:// www2.inca.gov.br/wps/wcm/connect/tiposdecancer/site/home/colo_utero/ definicao.

2. Kato T, Takashima A, Kasamatsu T, Nakamura K, Mizusawa J, Nakanishi $T$ et al. Clinical tumor diameter and prognosis of patients with FIGO stage IB1 cervical cancer (JCOG0806-A). Gynecol Oncol. 2015; 137(1):34-9.

3. Arimoto T, Kawana K, Adachi K, Ikeda Y, Nagasaka K, Tsuruga T et al. Minimization of curative surgery for treatment of early cervical cancer: a review. Jpn J Clin Oncol. 2015; 45(7):611-6.

4. Kokka F, Bryant A, Brockbank E, Jeyarajah A. Surgical treatment of stage IA2 cervical cancer. Cochrane Database Syst Rev. 2014; 5:CD010870.

5. Halaska MJ, Robova H, Pluta M, Rob L. The role of trachelectomy in cervical cancer. Ecancermedicalscience. 2015; 9:506.

6. Querleu D, Morrow CP. Classification of radical hysterectomy. Lancet Oncol. 2008; 9(3):297-303.

7. Bansal N, Herzog TJ, Shaw RE, Burke WM, Deutsch I, Wright JD. Primary therapy for early-stage cervical cancer: radical hysterectomy vs radiation. Am J Obstet Gynecol. 2009; 201(5):485.e1-9.

8. Shazly SA, Murad MH, Dowdy SC, Gostout BS, Famuyide AO. Robotic radical hysterectomy in early stage cervical cancer: a systematic review and meta-analysis. Gynecol Oncol. 2015; 138(2):457-71.

9. Petsuksiri J, Chansilpa Y, Therasakvichya S, Suntornpong N, Thephamongkhol $\mathrm{K}$, Dankulchai $\mathrm{P}$ et al. Treatment options in bulky stage IB cervical carcinoma. Int J Gynecol Cancer. 2008; 18(6):1153-62.
10. Yeo RM, Chia YN, Namuduri RP, Yap SP, Soong YL, Yam PK et al. Tailoring adjuvant radiotherapy for stage IB-IIA node negative cervical carcinoma after radical hysterectomy and pelvic lymph node dissection using the GOG score. Gynecol Oncol. 2011; 123 (2):225-9.

11. Minig L, Patrono MG, Romero N, Rodríguez Moreno JF, Garcia-Donas J. Different strategies of treatment for uterine cervical carcinoma stage IB2IIB. World J Clin Oncol. 2014; 5(2):86-92.

12. Rotman M, Sedlis A, Piedmonte MR, Bundy B, Lentz SS, Muderspach LI et al. A phase III randomized trial of postoperative pelvic irradiation in Stage IB cervical carcinoma with poor prognostic features: follow-up of a gynecologic oncology group study. Int J Radiat Oncol Biol Phys. 2006; 65(1):169-76

13. Monk BJ, Wang J, Im S, Stock RJ, Peters WA, Liu PY et al. Rethinking the use of radiation and chemotherapy after radical hysterectomy: a clinical-pathologic analysis of a Gynecologic Oncology Group/Southwest Oncology Group/ Radiation Therapy Oncology Group trial. Gynecol Oncol. 2005; 96(3):721-8.

14. Chemoradiotherapy for Cervical Cancer Meta-analysis Collaboration. Reducing uncertainties about the effects of chemoradiotherapy for cervical cancer: a systematic review and meta-analysis of individual patient data from 18 randomized trials. J Clin Oncol. 2008; 26(35):5802-12.

15. Fujiwara K, Monk B, Devouassoux-Shisheboran M. Adenocarcinoma of the uterine cervix: why is it different? Curr Oncol Rep. 2014; 16(12):416.

16. Favero G, Pierobon J, Genta ML, Araújo MP, Miglino G, Del Carmen Pilar Diz M et al. Laparoscopic extrafascial hysterectomy (completion surgery) after primary chemoradiation in patients with locally advanced cervical cancer: technical aspects and operative outcomes. Int J Gynecol Cancer. 2014; 24(3):608-14

17. Chemoradiotherapy for Cervical Cancer Meta-analysis Collaboration (CCCMAC). Reducing uncertainties about the effects of chemoradiotherapy for cervical cancer: individual patient data meta-analysis. Cochrane Database Syst Rev. 2010; (1):CD008285

18. Duenas-González A, Zarbá JJ, Patel F, Alcedo JC, Beslija S, Casanova L et al. Phase III, open-label, randomized study comparing concurrent gemcitabine plus cisplatin and radiation followed by adjuvant gemcitabine and cisplatin versus concurrent cisplatin and radiation in patients with stage IIB to IVA carcinoma of the cervix. J Clin Oncol. 2011; 29(13):1678-85.

19. Duenas-González A, Orlando M, Zhou Y, Quinlivan M, Barraclough H. Efficacy in high burden locally advanced cervical cancer with concurrent gemcitabine and cisplatin chemoradiotherapy plus adjuvant gemcitabine and cisplatin: prognostic and predictive factors and the impact of disease stage on outcomes from a prospective randomized phase III trial. Gynecol Oncol. 2012; 126(3):334-40.

20. Dizon DS, Mackay HJ, Thomas GM, Werner TL, Kohn EC, Hess D et al. State of the science in cervical cancer: where we are today and where we need to go. Cancer. 2014; 120(15):2282-8.

21. Tangjitgamol S, Katanyoo K, Laopaiboon M, Lumbiganon P, Manusirivithaya S, Supawattanabodee B. Adjuvant chemotherapy after concurrent chemoradiation for locally advanced cervical cancer. Cochrane Database Syst Rev. 2014; 12:CD010401.

22. Petrelli F, De Stefani A, Raspagliesi F, Lorusso D, Barni S. Radiotherapy with concurrent cisplatin-based doublet or weekly cisplatin for cervical cancer: a systematic review and meta-analysis. Gynecol Oncol. 2014; 134(1):166-71.

23. Ryu HS, Kang SB, Kim KT, Chang KH, Kim JW, Kim JH. Efficacy of different types of treatment in FIGO stage IB2 cervical cancer in Korea: results of a multicenter retrospective Korean study (KGOG-1005). Int J Gynecol Cancer. 2007; 17(1):132-6.

24. Rydzewska L, Tierney J, Vale CL, Symonds PR. Neoadjuvant chemotherapy plus surgery versus surgery for cervical cancer. Cochrane Database Syst Rev. 2010; (1):CD007406.

25. Eddy GL, Bundy BN, Creasman WT, Spirtos NM, Mannel RS, Hannigan E et al. Treatment of ('bulky') stage IB cervical cancer with or without neoadjuvant vincristine and cisplatin prior to radical hysterectomy and pelvic/para-aortic lymphadenectomy: a phase III trial of the gynecologic oncology group. Gynecol Oncol. 2007; 106(2):362-9.

26. Boutas I, Sofoudis C, Kalampokas E, Anastasopoulos C, Kalampokas T, Salakos N. Fertility preservation in women with early stage cervical cancer. Review of the literature. Eur J Gynaecol Oncol. 2014; 35(4):373-7.

27. Kyrgiou M, Mitra A, Arbyn M, Stasinou SM, Martin-Hirsch P, Bennett P et al. Fertility and early pregnancy outcomes after treatment for cervical intraepithelial neoplasia: systematic review and meta-analysis. BMJ. 2014; 349:g6192. 
28. Roque DR, Wysham WZ, Soper JT. The surgical management of cervical cancer: an overview and literature review. Obstet Gynecol Surv. 2014; 69(7):426-41.

29. Pareja R, Rendón GJ, Vasquez M, Echeverri L, Sanz-Lomana CM, Ramirez PT. Immediate radical trachelectomy versus neoadjuvant chemotherapy followed by conservative surgery for patients with stage IB1 cervical cancer with tumors $2 \mathrm{~cm}$ or larger: A literature review and analysis of oncological and obstetrical outcomes. Gynecol Oncol. 2015; 137(3):574-80. 30.

30. Buekers TE, Anderson B, Sorosky JI, Buller RE. Ovarian function after surgical treatment for cervical cancer. Gynecol Oncol. 2001; 80(1):85-8

31. Dursun P, Ayhan A, Yanik FB, Kuşçu E. Ovarian transposition for the preservation of ovarian function in young patients with cervical carcinoma. Eur J Gynaecol Oncol. 2009; 30(1):13-5.

32. Rasool N, Rose PG. Fertility-preserving surgical procedures for patients with gynecologic malignancies. Clin Obstet Gynecol. 2010; 53(4):804-14.

33. Chhabra S, Kutchi I. Fertility preservation in gynecological cancers. Clin Med Insights Reprod Health. 2013; 7:49-59.

34. Lécuru F, Mathevet P, Querleu D, Leblanc E, Morice P, Daraï E et al. Bilateral negative sentinel nodes accurately predict absence of lymph node metastasis in early cervical cancer: results of the SENTICOL study. J Clin Oncol. 2011; 29(13):1686-91.

35. Bats AS, Mathevet P, Buenerd A, Orliaguet I, Mery E, Zerdoud S et al. The sentinel node technique detects unexpected drainage pathways and allows nodal ultrastaging in early cervical cancer: insights from the multicenter prospective SENTICOL study. Ann Surg Oncol. 2013; 20(2):413-22.

36. Kadkhodayan S, Hasanzadeh M, Treglia G, Azad A, Yousefi Z, Zarifmahmoudi $\mathrm{L}$ et al. Sentinel node biopsy for lymph nodal staging of uterine cervix cancer: a systematic review and meta-analysis of the pertinent literature. Eur J Surg Oncol. 2015; 41(1):1-20

37. Tax C, Rovers MM, de Graaf C, Zusterzeel PL, Bekkers RL. The sentinel node procedure in early stage cervical cancer, taking the next step; a diagnostic review. Gynecol Oncol. 2015;pii:S0090-8258(15)30137-2.

38. Banerjee R, Kamrava M. Brachytherapy in the treatment of cervical cancer: a review. Int J Womens Health. 2014; 6:555-64.

39. Tanderup K, Viswanathan AN, Kirisits C, Frank SJ. Magnetic resonance image guided brachytherapy. Semin Radiat Oncol. 2014; 24(3):181-91.

40. Vargo JA, Beriwal S. Image-based brachytherapy for cervical cancer. World J Clin Oncol. 2014; 5(5):921-30.

41. Dutta S, Nguyen NP, Vock J, Kerr C, Godinez J, Bose S et al. Image-guided radiotherapy and brachytherapy for cervical cancer. Front Oncol. 2015; 5:64.

42. Harkenrider MM, Alite F, Silva SR, Small W Jr. Image-based brachytherapy for the treatment of cervical cancer. Int J Radiat Oncol Biol Phys. 2015; 92(4):921-34

43. Leath CA, Straughn JM Jr. Chemotherapy for advanced and recurrent cervical carcinoma: results from cooperative group trials. Gynecol Oncol. 2013; 129(1):251-7.

44. Pfaendler KS, Tewari KS. Changing paradigms in the systemic treatment of advanced cervical cancer. Am J Obstet Gynecol. 2015; pii:S0002-9378(15)00772-3.
45. Tomao F, Papa A, Rossi L, Zaccarelli E, Caruso D, Zoratto F et al. Angiogenesis and antiangiogenic agents in cervical cancer. Onco Targets Ther. 2014; 7:2237-48.

46. Jackson MW, Rusthoven CG, Fisher CM, Schefter TE. Clinical potential of bevacizumab in the treatment of metastatic and locally advanced cervical cancer: current evidence. Onco Targets Ther. 2014; 7:751-9.

47. Petit R, Basu P. ADXS11-001 immunotherapy targeting HPV-E7: preliminary survival data from a phase II study in Indian women with recurrent/refractory cervical cancer [abstract]. Presented at 2012 American Society of Clinical Oncology Annual Meeting; June 1-5, 2012; Chicago, IL.

48. Delpech Y, Tulpin L, Bricou A, Barranger E. Lymph node surgical staging for locally advanced cervical cancer. Gynecol Obstet Fertil. 2010; 38(1):30-5.

49. Uzan C, Gouy S, Pautier P, Haie-Meder C, Duvillard P, Narducci F et al. Paraaortic lymphadenectomy in advanced-stage cervical cancer: standard procedure in 2010?. Gynecol Obstet Fertil. 2010; 38(11):668-71.

50. Uzan C, Souadka A, Gouy S, Debaere T, Duclos J, Lumbroso J et al. Analysis of morbidity and clinical implications of laparoscopic para-aortic lymphadenectomy in a continuous series of 98 patients with advanced-stage cervical cancer and negative PET-CT imaging in the para-aortic area. Oncologist. 2011; 16(7):1021-7.

51. Smits RM, Zusterzeel PL, Bekkers RL. Pretreatment retroperitoneal paraaortic lymph node staging in advanced cervical cancer: a review. Int J Gynecol Cancer. 2014; 24(6):973-83.

52. Chantalat E, Vidal F, Leguevaque P, Lepage B, Mathevet P, Deslandres M et al. Cervical cancer with paraaortic involvement: do patients truly benefit from tailored chemoradiation therapy? A retrospective study on 8 French centers. Eur J Obstet Gynecol Reprod Biol. 2015; 193:118-22.

53. Hwang L, Bailey A, Lea J, Albuquerque K. Para-aortic nodal metastases in cervical cancer: a blind spot in the International Federation of Gynecology and Obstetrics staging system: current diagnosis and management. Future Oncol. 2015; 11(2):309-22.

54. Sardain H, Lavoue V, Redpath M, Bertheuil N, Foucher F, Levêque J. Curative pelvic exenteration for recurrent cervical carcinoma in the era of concurrent chemotherapy and radiation therapy. A systematic review. Eur J Surg Oncol. 2015; 41(8):975-85.

55. Ang C, Bryant A, Barton DP, Pomel C, Naik R. Exenterative surgery for recurrent gynaecological malignancies (Review). Cochrane Database Syst Rev. 2014; 2:CD010449.

56. Musto A, Grassetto G, Marzola MC, Chondrogiannis S, Maffione AM, Rampin L et al. Role of 18F-FDG PET/CT in the carcinoma of the uterus: a review of literature. Yonsei Med J. 2014; 55(6):1467-72.

57. Xiao Y, Wei J, Zhang Y, Xiong W. Positron emission tomography alone, positron emission tomography-computed tomography and computed tomography in diagnosing recurrent cervical carcinoma: a systematic review and meta-analysis. Arch Med Sci. 2014; 10(2):222-31.

58. Ding X, Feng L, Ma L. Diagnosis of recurrent uterine cervical cancer: PET versus PET/CT: a systematic review and meta-analysis. Arch Gynecol Obstet. 2014; 290(4):741-7. 